\title{
Oral genodermatoses
}

\author{
Akshat Sachdeva1 $^{1}$, Sumit Bhateja ${ }^{2 *}$, Geetika Arora ${ }^{3}$ \\ ${ }^{\mathbf{1}}$ Dental Surgeon, ${ }^{\mathbf{2}, 3}$ Reader, ${ }^{2}$ Dept. of Oral Medicine \& Radiology, ${ }^{\mathbf{3}}$ Dept. of Public Health Dentistry, ${ }^{\mathbf{1 , 2}}$ Manav Rachna Dental College, \\ Faridabad, Haryana, Inderprastha Dental College, Ghaziabad, Uttar Pradesh, India
}

\section{*Corresponding Author: Akshat Sachdeva}

Email: bhateja.sumit@gmail.com

\begin{abstract}
Genodermatoses alludes to a set of inherited dermatologic disorders. A significant variety of these disorders is unusual and present with oral indications called oral genodermatoses. They typically present with multisystem association prompting an expanded tempo of morbidity and mortality. The oral findings maybe perhaps distinct and may offer the primary clue of underlying genetic disorder. The present article discusses various genodermatomes presenting with oral manifestations and an approach to the diagnosis of these disorders.
\end{abstract}

Keywords: Genodermatoses, Dermatologic features, Oral manifestations, Genetics.

\section{Introduction}

Genodermatoses refers to a bunch of inherited disorders with skin manifestations. Several of these disorders have a rare incidence. Few present with certain oral manifestations as well and are hence referred to as oral genodermatoses. ${ }^{1}$ These disorders might vary from developmental disturbances of hard and soft tissues to precancerous and cancerous lesions. ${ }^{2}$ Rarity of these conditions can lead to complications in the diagnosis and management of these disorders.

Since the past few years, there has been a sudden explosion with regard to numerous innovations within the field of molecular biology which has appreciably transformed our current day expertise of pathogenesis of many human diseases.

\section{Classification}

There have been several proposed classifications of oral genodermatoses by various authors. Arora M et al (2016) classified oral manifestations of genodermatoses into six different groups as: ${ }^{3}$

1. Genodermatoses affecting teeth and dentition:
a. Icthyosis.
b. Sjogren-Larrson syndrome.
c. Incontinenia pigmenti.
d. Ehlers Danlos syndrome.
e. Focal dermal hypoplasia syndrome.
f. Gardner syndrome.
g. Ectodermal dysplasia.

2. Genodermatoses affecting periodontium and gingiva
a. Icthyosis.
b. Papillon Lefevre syndrome.
c. Tuberous sclerosis.
d. Chediak-Higashi syndrome.

3. Genodermatoses affecting oral mucosa:
a. Darier's disease.
b. Neurofibromatosis type 1 and 2 .
c. Multiple hamartoma syndrome.
d. Epidermolysis bullosa.
e. Pachonychia congenital.

4. Genodermatoses affecting jaw bones and facies:
a. McCune-Albright syndrome.
b. Marfan syndrome.
c. Gardner syndrome.
d. Basal cell nevus syndrome.

5. Genodermatoses causing pigmentation of oral mucosa:
a. Neurofibromatosis type 1 and 2 .
b. Peutz-Jeghers syndrome.
c. Hereditary hemorrhagic telangiectasia syndrome.

6. Genodermatoses with malignant potential:
a. Xeroderma pigmentosum.
b. Dyskeratosis congenita.

According to Irvine and Mellerio, oral genodermatoses can be classified as: ${ }^{4}$

1. Inherited immunobullous disorders:

a. Epidermolysis bullosa of different groups.

2. Disorders of keratinization:
a. Icthyosis.
b. Follicular keratosis.
c. Palmoplantar keratoedema.

3. Hereditary disorders of pigmentation:
a. Carney complex.
b. Chediak-Higashi syndrome.

4. Familial multiple tumor syndrome:

a. Neurofibromatosis type 1 and 2.

b. Tuberous sclerosis complex.

c. Gardner syndrome.

d. Cowden syndrome.

e. Peutz-Jeghers syndrome.

5. Ectodermal dysplasia and disorders of ectodermal appendages.

6. Disorders with defects in DNA repair and chromosomal instability:
a. Bloom syndrome.
b. Xerodermapigmentosum.

7. Poikilodermatous diorders:
a. Rothmund Thomson syndrome.
b. Dyskeratosis congenital.
c. Kindler syndrome.

8. Connective tissue disorders: 
b. Marfan syndrome.

c. Pseudoxanthoma elasticum.

9. Vascular and lymphatic disorders:

a. Osler-Rendu-Weber syndrome type 1 and 2.

10. Porphyrias.

11. Disorders associated with immunodeficiency:
a. Wiskott-Aldrich syndrome.

12. Miscellaneous disorders:
a. Goltz syndrome.
b. Nail-patella syndrome.
c. Apert syndrome.

There are many genetic disorders affecting the mouth and adjoining areas. Few of them along with their oral manifestations have been discussed:

\section{Epidermolysis Bullosa}

Epidermolysis bullosa refers to a group of heritable genetic diseases having three major varieties particularly simple, junctional and dystrophic. ${ }^{5}$ It is characterized by blister formation and scarring. Flat, pink bullae on ankles, knees, hands, elbow and feet are visible. Maximum instances are associated with anchoring filaments and anchoring fibrils which gives rise to an interconnecting network. In addition, mutations of gene coding for type VII collagen of anchoring fibrils have likewise been distinguished. ${ }^{6}$

Oral Manifestations: Oral involvement has been observed in junctional and dystrophic forms of the disease. Few sufferers have shown to evince oral bullae and milia formation. ${ }^{7}$

\section{Peutz-Jeghers Syndrome}

It is an autosomal dominant ailment characterized by formation of gastrointestinal polyps and maculae. ${ }^{8}$ Mutation of the gene LKB1/STK11 (serine/threonine-protein kinase 11 ) is accountable for its causation. ${ }^{9}$ The condition typically includes the periorofacial areas (mouth, nose). Gastrointestinal adenocarcinoma may develop in 2-3\% of affected individuals. Patients stricken by this disorder have a nearly $50 \%$ threat of passing on the mutation to each of their progeny. ${ }^{10}$

Oral Manifestations: Pigmented lesions on the skin around lips and vermilion zone are commonly seen. Brown pigmented macules are usually present during childbirth or noted in early adolescence. ${ }^{11}$ Lesions are viewed as painless patches on buccal or labial mucosa and tongue.

\section{Ehlers-Danlos Syndrome}

It refers to a collection of inherited connective tissue disorders. The condition occurs as a result of an imperfection in collagen amalgamation. It mostly influences joints, skin and vessels. Nearly half of the affected individuals have a mutation in COL5A1 or COL5A2. ${ }^{1}$

Oral Manifestations: Extra-oral signs consist of slender and uneven face, scars on the skin and forehead and repeated incidence of TMJ dislocation. Intra-oral manifestations comprise of high arched palate, crowding of teeth and fragile mucosa seen with bruising. ${ }^{12}$

\section{Marfan's Syndrome}

Marfan's disorder is a hereditary condition of the connective tissue and has appeared to display visual, skeletal and cardiovascular signs. People influenced with the disorder will in general be abnormally tall with lengthy appendages. Spine curves on one side called scoliois. ${ }^{1}$ Severe complications like aortic aneurysms and left ventricular dysfunction have likewise been seen. Syndrome is carried by the gene FBN1 that encodes fibrillin-1 inherited as a dominant trait. ${ }^{13}$

Oral Manifestations: Jaw bones present with retrognathia, crowding of teeth. Root distortion and irregular pulp shapes have been every now and again watched. ${ }^{12}$

\section{Gardner's Syndrome}

It is an uncommon autosomal dominant disorder portrayed by intestinal polyposis, sebaceous cysts and jaw osteomas. It has been related to $X$ gene located in chromosome 5q21.14 The condition is also associated with epidermoid cysts, eye abnormalities and malignancies like thyroid carcinomas and adenocarcinomas. The condition is usually asymptomatic.

Oral Manifestations: Multiple supernumerary peg shaped and unerupted teeth are present in the incisor, cuspid and bicuspid region. Compound odontomas are usually seen in the same manner as supernumerary teeth. Osteomas can also be felt through the skin and oral mucosa. ${ }^{15}$

\section{Cowden Syndrome}

Also known as "multiple hamartoma syndrome". It is an autosomal dominant disorder having multiple tumor-like growths called hamartomas. They are characterized by mucocutaneous papules involving oral, nasal and intestinal mucosa. ${ }^{16}$ Patients suffering from Cowden's syndrome are also prone to developing cancers including breast, thyroid and uterus. Mutation in the PTEN gene is the causative factor for the syndrome discovered in majority of patients. ${ }^{17}$

Oral Manifestations: Oral findings include presence of hamartomas on gingiva, buccal and palatal mucosa. Appearance of multiple mucosal papules has been described as cobblestone-like seen in about $40 \%$ of patients. ${ }^{18}$.

\section{Neurofibromatosis}

Neurofibromatosis is inherited as an autosomal dominant trait. It is a neurocutaneous disorder ordered into two sorts: neurofibromatosis 1 (NF1) and neurofibromatosis 2 (NF2). ${ }^{19}$ NF1 is also called as von Recklinghausen disease. It is characterized by presence of numerous café-au-lait spots more noteworthy than $0.5 \mathrm{~cm}$ in diameter. NF1 affects 1 in 3500 individuals worldwide and is caused by mutation on chromosome 17q11.2. NF2 is commonly known as bilateral acoustic neurofibromatosis. Identifying features of NF2 include bilateral schwannomas involving eighth cranial nerve and lesions on brain and spinal cord. ${ }^{19} \mathrm{NF} 2$ is caused due to mutation on chromosome 22q12.2.

Oral Manifestations: Oral soft tissue neurofibromas are located in the soft tissues such as cheek, tongue, floor of mouth and lips with tongue being the most commonly affected part. ${ }^{20}$ Superficial lesions give the tongue a scrotal 
or fissured appearance, while deep seated tumors give appearance of macroglossia.

\section{Dyskeratosis Congenita}

The disorder is an $\mathrm{X}$-linked recessive one and is characterized by a classical triad of nail dystrophy, lacy cutaneous pigmentations and oral leukoplakia. Affected individuals have a high tendency for malignancies and subsequent bone marrow failure. Malignancy often develops in the third decade of life..$^{21}$ Bone marrow failure can lead to thrombocytopenia, anemia and ophthalmic abnormalities. Significantly shortened lifespan has been seen in individuals affected with more serious form of the disorder. ${ }^{22}$ The condition occurs as a result of one or more mutations in the long arm of the $\mathrm{X}$ chromosome in gene $\mathrm{DKC} 1$.

Oral Manifestations: Leukoplakia involving lingual \& buccal mucosa and palate has been observed in majority of affected patients. The lesion may progressively become verrucous and ulcerated. An increased incidence of periodontal disease and dental caries has also been observed. $^{22}$

\section{Hemorrhagic Telangiectasia}

It is also known as Osler-Weber-Rendu syndrome. It is a rare autosomal dominant disorder leading to abnormal vessel formation affecting the skin and mucous membranes. Certain arteriovenous malformations become more prominent with advancing age. Two genetic types have been observed: HHT-1 and HHT-2.

Oral Manifestations: Oral lesions maybe nodular and can be seen on buccal mucosa, tongue, lips and gingiva. ${ }^{23}$ Shading may fluctuate from brilliant red to purple.

\section{MEN's Syndrome}

Multiple endocrine neoplasia (MEN) syndrome is an uncommon autosomal prevailing issue related with neoplasm of endocrine gland. Two main types have been identified: MEN-I and MEN-II. MEN-I is portrayed by tumor of pituitary organ and pancreas. MEN-II is portrayed by various pheochromocytomas and thyroid carcinomas. MEN is associated with oncogenic point mutations of RET proto-oncogene on chromosome locus 10q11.2. ${ }^{1}$

Oral Manifestations: Oral lesions present as nodular or diffuse swellings in the oral cavity. This feature is pathognomonic and hence also called as "multiple mucosal neuroma syndrome". This oral manifestation is often the first clue to the syndrome at an early age. ${ }^{24}$

\section{Diagnosis of Genodermatoses}

It is rightly quoted as "the skin frequently mirrors systemic genetic diseases". Genodermatoses are rare skin conditions for which a multistep approach is required to diagnose them. ${ }^{25}$

\section{Recognize "Red Flags"}

Cutaneous findings can represent significant clues for identifying a syndrome. Persistent erythroedema at birth might be associated with hereditary disorders like icthyosis.
Cutaneous findings inconsistent with the patient's age, such as loose, hanging skin in a newborn or cutaneous malignancy in a child are strongly suggestive of a genetic skin disorder. Clinical presentation of many genodermatoses changes with the patient's age and some genetic disorders manifest only in adolescence or adulthood.

\section{Obtain thorough medical history}

Family history has often been called "the first genetic test" the physician should examine first- and second-degree relatives, or obtain clinical pictures and medical documents, in order to be able to recognize subtle phenotypic features. The country of origin, and in particular ethnicity, may affect the molecular and clinical presentation of some genetic pigmented disorders. For e.g.: positive family history in a young adult with blisters and erosions in the large folds points to the diagnosis of Hailey-Hailey disease. Many genodermatoses occur sporadically as a result of new mutations. ${ }^{25}$

\section{Perform complete physical examination}

Identification of skin changes and appendages are helpful in narrowing the differential diagnosis and sometimes even in determining the final diagnosis. Congenital anomalies and extracutaneous findings may point to a specific diagnosis. Early diagnosis of a genetic disorder may prompt adequate clinical follow-up and early treatment of systemic manifestations.

\section{Laboratory testing}

Skin biopsies should be obtained for histopathology, including special stains and immunochemistry, electron microscopy, and/or cell cultures. Histopathology is crucial in determining the morphology of cutaneous features, and frequently facilitates establishing the correct diagnosis. Biochemical and enzymatic tests are important tools in the diagnostic workup of metabolic diseases and primary nutritional disorders associated with cutaneous symptoms.

\section{Nails as Diagnostic Clue}

Appendageal structures like nails can act as good reflectors for presence of many systemic disorders. Nails may be the affected primary site in some genodermatoses. Nail involvement maybe categorized into three groups: ${ }^{27}$

1. Genodermatoses with characteristic nail changes: Few genodermatoses present with trademark nail changes. When experienced with such nail changes, these clutters merit the principal demonstrative thought. Examples include: pachonychia congenital, nail-patella syndrome, yellow nail syndrome, Darier's disease and porphyrias.

2. Genodermatoses with significant nail involvement: A few genodermatoses have nail changes sufficiently noteworthy to stand out for clinician during first visit, however not normal for these clutters. Examples include: epidermolysis bullosa, dyskeratosis congenital, Kindler syndrome and incontinentia pigmenti. 
3. Genodermatoses with nonspecific nail changes: These progressions are not pointers of a particular hereditary issue and might be seen even in many gained conditions. Examples include: ectodermal dysplasia, Peutz-Jeghers syndrome, icthyosis, neurofibromatosis type 1 and palmoplantar keratoedema.

There is no specific effective treatment for genodermatoses. Causative genes ought to be distinguished and focused by gene replacement therapy. PreNatal Diagnosis might be picked to evaluate the high hazard for extreme instances of genodermatoses. Estimation of genetic risk should be highly accurate. Genetic counselling is the procedure of counsel where the patient or family is given data on the kind of legacy, danger of event, forecast of an ailment, anticipation and treatment. Genetic counselling ought to be painstakingly accomplished for patients and their families and they ought to be furnished with exact data on the maladies.

\section{Conclusion}

There is presently better comprehension of the hereditary premise of genodermatoses with enormous advancement in their molecular diagnosis. Some innovative stratergies are needed to be undertaken at the molecular level. Molecular testing is vital for confirming the diagnosis, identifying new genes and sometimes even new diseases and understanding its pathogenesis. Oral genodermatosis registry should be initiated to know the frequency and to create novel preventive and helpful apparatuses.

\section{Source of funding}

None.

\section{Conflict of interest}

None.

\section{References}

1. Kumar K, Shilpasree AS, Chaudhary M. Oral Manifestations and Molecular Basis of Oral Genodermatoses: A Review. $J$ Clin Diagn Res 2016; 10(5):08-12.

2. Kavya S, Vandana S, Paulose S, Rangdhol V, Baliah WJ, Dhanraj T. Oral manifestation of genodermatoses. J Med, Radiol, Pathol Surg 2017; 4(3):22-7.

3. Arora M, Mane D. A Proposed Classification to Identify the Oral Manifestations of Genodermatoses. J Coll Physicians Surg Pak 2016;26(7):636-7.

4. Irvine AD, Mellerio JE. Genetics and genodermatoses. In: Burns T, Breathnach S, Cox N, Griffiths C, editors. Rook's Textbook of Dermatology. 8th ed. Oxford: Blackwell Science; 2010. p. 15.1-15.97.

5. Babu NA, Rajesh E, Krupaa J, Gnananandar. Genodermatoses. $J$ Pharm Bioall Sci 2015;7:5203-6.

6. McGrath JA, Mellerio JE. Epidermolysis bullosa. Br J Hosp Med. (Lond). 2006; 67(4):188-91.

7. Andreasen JO, Hjorting-Hansen E, Ulmansky M, Pindborg JJ. Milia formation in oral lesions in epidermolysis bullosa. Acta Pathol Microbiol Scand 1965;63:37-41.

8. Kitagawa S, Townsend BL, Hebert AA. Peutz-Jeghers' syndrome. Dermatol Clin 1995;13(1):127-31.
9. McGarrity TJ, Amos C. Peutz-Jeghers syndrome: clinicopathology and molecular alterations. Cell Mol Life Sci 2006;63(18):2135-44.

10. Gavren BA, Lumerman H, Cardo VA, Schmidt BL. Multiple pigmented lesions of the lower lip. J Oral Maxillofac Surg 2002;60(4):438-45.

11. McGarrity TJ, Amos C. Peutz-Jeghers syndrome: clinicopathology and molecular alterations. Cell Mol Life Sci 2006;63(18):2135-44.

12. Welbury RR. Ehers-Danlos syndrome: historical review, report of two cases in one family and treatment needs. ASDC J Dent Child 1989;56(3):220-4.

13. Harton GL, Tsipouras P, Sisson ME, Starr KM, Mahoney BS, Fugger EF, et al. Preimplantation genetic testing for Marfan syndrome. Mol Hum Reprod 1996;2(9):713-5.

14. Gardner EJ. A genetic and clinical study of intestinal polyposis, a predisposing factor for carcinoma of the colon and rectum. Am J Hum Genet 1951; 3(2):167-76.

15. Ida M, Nakamura T, Utsunomiya J. Osteomatous changes and tooth abnormalities found in the jaws of patients with adenomatosis coli. Oral Surg Oral Med Oral Pathol 1981;52(1):2-11.

16. Schenberg ME, Zajac JD, Lim-Tio S, Collier NA, Brooks AM, Reade PC. Multiple endocrine neoplasia type 2b. Int J Oral Maxillofac Surg 1992; 21(2):110-4.

17. Eng C, Hampel H, De la Chapelle A. Gene testing for cancer predisposition. Anпи Rev Med 2001;52:371-400.

18. Hildebrand C, Burgdorf WH, Lautenschlager S. Cowden syndrome- diagnostic skin signs. Dermatol 2001; 202(4):3626.

19. Uhlmann EJ, Plotkin SR. Neurofibromatoses. Adv Exp Med Biol 2012;724:266-77.

20. Cherrick HM, Eversole LR. Benign neural sheath neoplasm of the oral cavity. Report of 37 cases. Oral Surg Oral Med Oral Pathol 1971; 32(6):900-09.

21. Vulliamy T, Marrone A, Goldman F, Dearlove A, Bessler M, Mason PJ et al. The RNA component of telomerase is mutated in autosomal dominant dyskeratosis congenita. Nat 2001;413(6854):432-5

22. Handley TP, McCaul JA, Ogden GR. Dyskeratosis congenita. Oral Oncol 2006;42(4):331-6.

23. Bartolucci EG, Swan RH, Hurt WC. Oral manifestations of hereditary hemorrhagic talengiectasia. Rev Case Rep J Periodontal. 1982;53(3):163-7.

24. Morrison PJ, Nevin NC. Multiple endocrine neoplasia type IIB (mucosal neuroma syndrome or wagen-mann froboese syndrome). J Med Genet 1996;33(9):779-82.

25. Tentcheva-Poor I, Oji V, Has C. A multistep approach to the diagnosis of rare genodermatoses. J Ger Soc Dermatol 2016;14(10):969-86.

26. Guttmacher A, Collins FS, Carmona RH. The family history more important than ever. N Engl J Med 2004;351:2333-6.

27. Inamadar AC, Palit A. Nails: Diagnostic clue to genodermatoses. Indian J Dermatol Venereol Leprol 2012;78:271-8. 